\section{Commentary: It's not that we can't find a solution, it's that we can't isolate the problem}

\author{
Bahaaldin Alsoufi, MD
}

In the current issue of the Journal, Liu and colleagues ${ }^{1}$ from Shanghai present their elegant study examining the effect of chronic hypoxia on brain development. They used 3-dayold rats for their animal model since their white matter development during this period is comparable with that of human fetuses during the third trimester of pregnancy. They created 3 study groups: normoxia control, chronic hypoxia, and chronic hypoxia plus progesterone therapy. They assessed motor skills and coordination abilities via rotation experiments and compared the brains in the sacrificed samples (14 days old) using hematoxylin and eosin staining, immunohistochemistry, real-time quantitative polymerase chain reaction, and Western blot analyses. Their findings were the following: (1) Rats exposed to chronic hypoxia performed poorly compared with controls and displayed brain development abnormalities (lower brain weight, white matter loss, ventricular enlargement). (2) Rats that received progesterone during chronic hypoxia performed better and displayed improved brain maturity (better brain weight, less white mater loss, and less ventricular enlargement). (3) The effect of progesterone therapy on white matter development was related to promotion of mature oligodendrocytes and myelin basic protein expression and that was the result of changes in M1 and M2 microglial polarization (attenuation of the damaging proinflammatory M1 and promotion of the protective antiinflammatory M2). Based on their findings, the authors

\footnotetext{
From the Department of Cardiovascular and Thoracic Surgery, University of Louisville School of Medicine, Norton Children's Hospital, Louisville, Ky.

Disclosures: The author reported no conflicts of interest.

The Journal policy requires editors and reviewers to disclose conflicts of interest and to decline handling or reviewing manuscripts for which they may have a conflict of interest. The editors and reviewers of this article have no conflicts of interest.

Received for publication April 12, 2020; revisions received April 12, 2020; accepted for publication April 13, 2020; available ahead of print May 4, 2020.

Address for reprints: Bahaaldin Alsoufi, MD, Department of Cardiovascular and Thoracic Surgery, University of Louisville School of Medicine, Norton Children's Hospital, 201 Abraham Flexner Way, Suite 1200, Louisville, KY 40202 (E-mail: balsoufi@hotmail.com).

J Thorac Cardiovasc Surg 2020;160:e69-70

$0022-5223 / \$ 36.00$

Copyright (C) 2020 by The American Association for Thoracic Surgery

https://doi.org/10.1016/j.jtcvs.2020.04.105
}

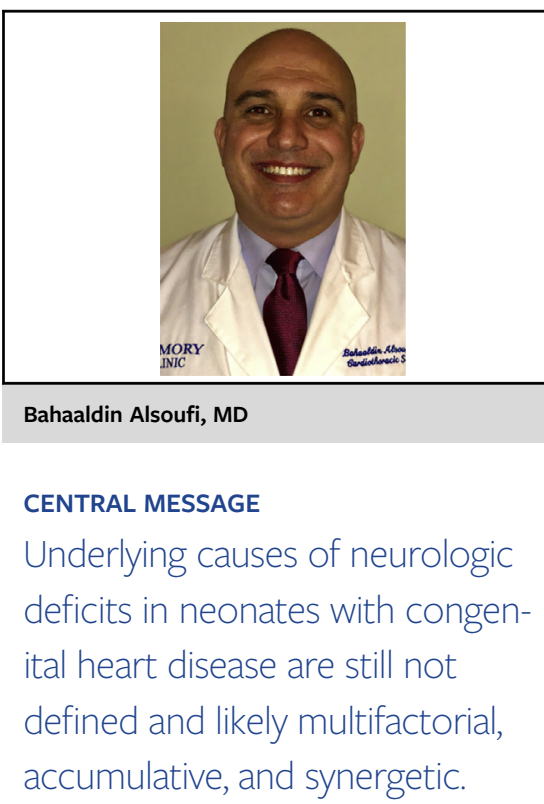

postulated that intrauterine or preoperative progesterone administration might improve neurologic development in neonates undergoing surgery for cyanotic congenital heart disease.

The major advances in surgical techniques and perioperative care have led to remarkable improvements in early and late survival and resulted in a shift in attention to quality of life and functional outcomes. The association between congenital heart disease and long-term neurologic deficits is well recognized and linked to abnormalities in brain maturation. ${ }^{2-4}$ Despite the specific interest in neurologic development, investigation efforts related to this subject are still in early stages. The origin of these neurologic deficits is still not well understood; although the initial thought was that this is an acquired insult during the perioperative period, it has become increasingly evident that this process starts much earlier during fetal development. $^{5-7}$ Modern neurologic monitoring and imaging techniques have demonstrated important brain abnormalities in neonates with major congenital heart defects even before any surgical intervention. ${ }^{5-7}$ Consequently, it is highly likely that the underlying causes of altered brain maturation are multifactorial, combining primary and newly acquired brain injuries, and that the effects of those factors are accumulative and synergistic. The brain development is a long and vigorous process that starts in the first month of gestation and continues into adulthood, with particular growth during the first 1 to 2 years of life. ${ }^{5-7}$ Therefore, children with 
congenital heart disease might be prone to interruptions in neurologic development at various stages, with subsequent neurologic impairment. The incidence of prematurity, low birth weight, and genetic syndromes in neonates born with major congenital heart defects is exceptionally high, and there is a strong relationship between those factors and brain development involving both gray and white matter. ${ }^{8-11}$ In addition, prematurity and low birth weight are associated with greater morbidity and mortality and prolonged recovery following cardiac surgery. ${ }^{8}$ The exaggerated systemic inflammatory response in these patients is linked to this morbidity, including white matter injury. Needless to say, genetic syndromes are associated with major changes in all organ development, including the heart and the brain. ${ }^{10,11}$ In addition, disturbances in brain blood flow in utero and after birth in the setting of congenital heart disease have been shown to affect brain size and development. ${ }^{12,13}$ Chronic hypoxia, as demonstrated again in the current study by Liu and colleagues, ${ }^{1}$ can impair brain maturity through a complex phenomenon. Additional better-studied elements that affect perioperative brain blood flow incorporate anesthesia, perfusion, and postoperative support; all of these can play significant roles in the development of supplementary neurologic injury. ${ }^{14}$

In summary, significant gaps in our knowledge of brain development exist, and direct connections between specific factors and neurologic deficits are not well established. Our inability to correctly define and isolate the problem continues to hinder our power to find a solution that can effectively improve neurologic outlook in these children. Numerous studies, similar to the one presented by Liu and colleagues, are needed to learn more about this complex process. It is highly unlikely that a single factor is responsible for the distorted brain maturation and therefore a single therapy, such as progesterone as advocated by Liu and colleagues, is unlikely to be effective alone in completely mitigating all-cause neurologic injury. Nonetheless, this is definitely a step in the right direction on a very long stairway.

\section{References}

1. Liu G, Yan Y, Shi B, Huang J, Mu H, Li C, et al. Benefits of progesterone on brain immaturity and white matter injury induced by chronic hypoxia in neonatal rats. J Thorac Cardiovasc Surg. 2020;160:e55-66.

2. Gaynor JW, Stopp C, Wypij D, Andropoulos DB, Atallah J, Atz AM, et al. Neurodevelopmental outcomes after cardiac surgery in infancy. Pediatrics. 2015;135: 816-25.

3. Marino BS, Lipkin PH, Newburger JW, Peacock G, Gerdes M, Gaynor JW, et al. Neurodevelopmental outcomes in children with congenital heart disease: evaluation and management: a scientific statement from the American Heart Association. Circulation. 2012;126:1143-72.

4. Bellinger DC, Wypij D, Rivkin MJ, DeMaso DR, Robertson RL Jr, DunbarMasterson C, et al. Adolescents with d-transposition of the great arteries corrected with the arterial switch procedure: neuropsychological assessment and structural brain imaging. Circulation. 2011;124:1361-9.

5. Andropoulos DB, Hunter JV, Nelson DP, Stayer SA, Stark AR, McKenzie ED, et al. Brain immaturity is associated with brain injury before and after neonatal cardiac surgery with high-flow bypass and cerebral oxygenation monitoring. $J$ Thorac Cardiovasc Surg. 2010;139:543-56.

6. Knickmeyer RC, Gouttard S, Kang C, Evans D, Wilber K, Smith JK, et al. A structural MRI study of human brain development from birth to 2 years. J Neurosci. 2008;28:12176-82.

7. Miller SP, McQuillen PS, Hamrick S, Xu D, Glidden DV, Charlton N, et al. Abnormal brain development in newborns with congenital heart disease. $N$ Engl J Med. 2007;357:1928-38.

8. Alsoufi B, Manlhiot C, Mahle WT, Kogon B, Border WL, Cuadrado A, et al. Low weight infants are at increased mortality risk following palliative or corrective cardiac surgery. J Thorac Cardiovasc Surg. 2014;148:2508-14.

9. Counsell SJ, Boardman JP. Differential brain growth in the infant born preterm: current knowledge and future developments from brain imaging. Semin Fetal Neonatal Med. 2005;10:403-10.

10. Alsoufi B, Gillespie S, Mahle WT, Deshpande S, Kogon B, Maher K, et al. The effect of non-cardiac and genetic abnormalities on outcomes following neonatal congenital heart surgery. Semin Thorac Cardiovasc Surg. 2016;28:105-14.

11. Gaynor JW, Gerdes M, Zackai EH, Bernbaum J, Wernovsky G, Clancy RR, et al. Apolipoprotein E genotype and neurodevelopmental sequelae of infant cardiac surgery. J Thorac Cardiovasc Surg. 2003;126:1736-45.

12. Licht DJ, Wang J, Silvestre DW, Nicolson SC, Montenegro LM, Wernovsky G, et al. Preoperative cerebral blood flow is diminished in neonates with severe congenital heart defects. J Thorac Cardiovasc Surg. 2004;128:841-9.

13. Sun L, Macgowan CK, Sled JG, Yoo SJ, Manlhiot C, Porayette P, et al. Reduced fetal cerebral oxygen consumption is associated with smaller brain size in fetuses with congenital heart disease. Circulation. 2015;131:1313-23.

14. Alsoufi B, Bennetts J, Verma S, Caldarone CA. New developments in the treatment of hypoplastic left heart syndrome. Pediatrics. 2007;119:109-17. 